\title{
Formulation and simulation of a hybrid solar PV-wind generation system with photovoltaic concentration for non-interconnected areas to the energy grid
}

\author{
José Luis Torres-Madroñero ${ }^{1, *}$, Jorge Mario Tamayo-Avendaño ${ }^{1}$, Santiago Bernal-del Río ${ }^{3}$, Julián Sierra-Pérez ${ }^{1}$, César \\ Nieto-Londoño ${ }^{2}$, Ricardo Mejía-Gutiérrez ${ }^{3}$, and Gilberto Osorio-Gómez ${ }^{3}$ \\ ${ }^{1}$ Grupo de Investigación en Ingeniería Aeroespacial, Universidad Pontificia Bolivariana, 050031 Medellín, Colombia \\ ${ }^{2}$ Grupo de Energía y Termodinámica, Universidad Pontificia Bolivariana, 050031 Medellín, Colombia \\ ${ }^{3}$ Design Engineering Research Group (GRID), EAFIT University, 050022, Medellín, Colombia
}

\begin{abstract}
Different isolated systems with conventional generation sources are installed in NonInterconnected Areas (ZNI) in Colombia while off-grid renewable systems are a trending answer for the energy supply in these regions. The complementarity between different energy sources, a storage system and adequate control can substantially improve the reliability of isolated generation systems. In this context, the sizing of a Hybrid Renewable Energy System (HRES) by means of a Genetic Algorithm (GA) is presented, considering the wind and solar resources specific to a representative rural location in Colombia. The methodology involves power curves for small wind turbines and the model for photovoltaic solar panels. The preliminary output consists of a weighted distribution for each technology, either wind or conventional photovoltaics, and is constrained by the Loss of Power Supply Probability (LPSP) and the Levelized Cost Of Electricity (LCOE). A second step consists of the optimization of the installed area for photovoltaic generation, considering a Concentrated Photovoltaic (CPV) system and aiming to maintain the initial fraction of generation for this resource. Finally, an analysis is performed on the reduction of area for solar generation to the increase in costs derived from the use of concentrators and other penalties associated with this technology.
\end{abstract}

\section{Introduction}

About $80 \%$ of the worldwide energy demand is supplied from fossil resources and only $20 \%$ from renewable sources, where hydroelectric power and biomass stand out. Fossil resources are characterized by being finite and their use in final energy generation causes greenhouse gas emissions and environmental pollution, creating the need to use clean and renewable technologies. In the Colombian context, renewable energy sources represent at least $85 \%$ of the total generation, being hydro the principal source [1].

Wind power had the greatest worldwide diffusion with $513 \mathrm{GW}$ of installed capacity in 2017, while solar photovoltaic and thermal energy had $389 \mathrm{GW}$ in the same year [2]. In Colombia, the wind resource is favorable in the Caribbean region, and some specific areas of the center region. The solar resource on the other hand, has a nationwide average irradiation of $4.5 \mathrm{kWh} / \mathrm{m}^{2} / \mathrm{d}$, greater than the world average of $3.9 \mathrm{kWh} / \mathrm{m}^{2} / \mathrm{d}$ [1].

The disadvantage of wind and solar resources is their variability over time. However, if a hybrid system design integrates these two energy sources to a storage system, it is possible to meet the energy demand of a region [3]. Optimal HRES size and location in regions where electricity supply is not covered, implies a better quality of life. The implementation of a HRES also improves the access to energy, furthermore, the energy equity and environmental sustainability are promoted, including all the qualification indicators of the energy sector given by the World Energy Council [4]. In this sense, this work focuses on the sizing of a HRES for a ZNI in the Colombian territory involving the electricity generation by wind and solar resources, coupled to a supporting battery bank. For this purpose, the sizing is carried out by a GA, where the best solution according to the LPSP and the LCOE will be treated for optimizing the area using CPV.

\section{Background}

This section shows some related works about GA for HRES sizing and CPV to improve the radiation density and reduce the operation area of PV technologies. Recent works in sizing of HRES use meta-heuristic methods as a way of finding a solution which is not necessarily the optimum but is an adequate approximation. This kind of approaches are still built on rigorous optimization methods which find a best solution for the involved variables while fulfilling an objective function [5]; they answer to the problematic of treating physical phenomena

* Corresponding author: jose.torresm@upb.edu.co 
for which no reliable nor practical mathematical models are yet available as explained by Twaha and Ramli [6]. Wind energy applications can often involve diverse phenomena, making meta-heuristic methods an attractive choice. Two of these methods are Particle Swarm Optimization (PSO), inspired by the behavior of flocks of birds and fish [6] and GA which combines exhaustive search techniques and the natural principles of evolution [7]. Their popularity for sizing of HRES is highlighted in the work of Khare et al. [8]. In this sense, different works have used GA for the sizing of systems that often involve solar and wind energy along with a battery bank. This is the case of Khatib et al. [9] which use an iterative search and GA. Merei et al. [10] presents a similar work including a diesel generator and three different battery technologies. Kamjoo et al. [11] uses a method for nondominant genetic classification that aims to minimize total system cost while maximizing reliability.

An alternative to traditional PV panels are CPV systems, which can be integrated into the design of buildings and have recently gained relevance in residential applications [12], due to the increase in density radiation that goes to the receiver, and the consequential improvement in the effective use of available area. The results shown by Xuan et al. [13] support the previous argument as they reveal an increase in maximum power of $158.7 \%$ under experimental tests. Hadavinia and Singh [14] discuss the increase in performance of PV systems by using low concentration systems such as V-Through (VT) and Compound Parabolic Concentration (CPC). Low concentration systems are attractive to small scale applications as the potential increase in temperature has a small effect on the performance of the cell [15]. For this reason, VT devices with a concentration ratio $\left(C_{r}\right)$ below a value of 3 result in a significant cost-benefit rate for these systems [16]. Many of the models for PV and CPV systems use ray tracing methods, based on geometric optics [17] and comprise a wide variety of tools for the modelling of CPV systems [18] such as VTDesign ${ }^{\circledR}$ which is used here.

\section{Formulation}

This section presents the mathematical formulation of wind and PV power generation and also the model for the state of the battery. In order to assess the power output with respect to the regional demand, both LPSP and LCOE are considered as technical and economic indicators, respectively. Several authors, model the power output from a wind turbine in terms of the air density, $\rho$, rotor sweep area, $A$, wind speed, $v$ and power coefficient, $C p$ according to the Equation 1 [19]:

$$
P_{w t}(v)=\frac{1}{2} C_{p} \rho A v^{3},
$$

The details of this model can vary as the $C p$ is defined in terms of the control system. For that reason the measured power curve of four turbines has been considered here [20]-[23] and presented in Figure 1. Given the size in power output for these turbines, an average installed cost of US\$7500 per $\mathrm{kW}$ can be assumed [24]. From the considered wind turbines, the Model 2 stands out because of the inferior total installed cost, associated to the smaller rated power. On the other hand, the Model 4 differs from the rest because of its control strategy, which results in a visible power reduction as the wind speed increases beyond the peak value.

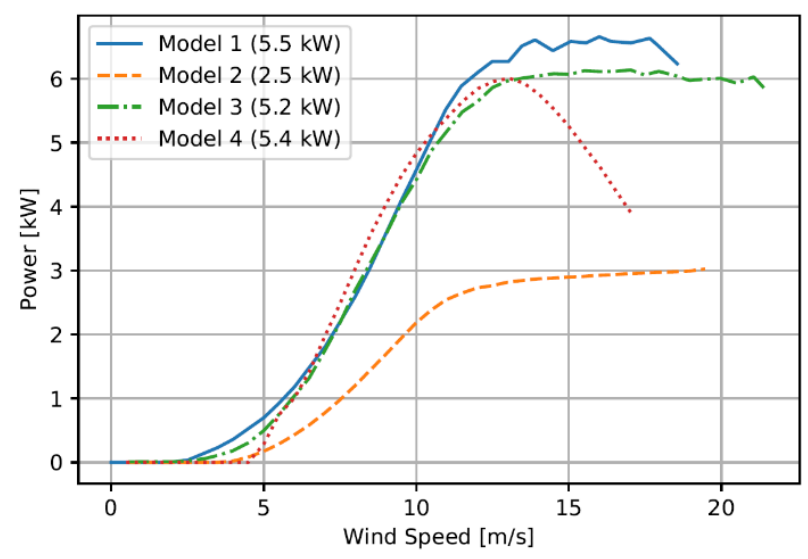

Fig. 1. Measured power curves for the considered machines.

The power generated by a PV solar panel is given by Equation 2 [25]:

$$
\begin{aligned}
P_{p v}(t) & =P_{p v r} \frac{R}{R_{\text {ref }}}\left(1+N_{T}\left(T_{c}-T_{\text {ref }}\right)\right), \\
T_{c} & =T_{\text {air }}+\left(\left(\frac{\text { NOCT }-20}{800}\right) R\right),
\end{aligned}
$$

where $P_{p v r}$ is the power rated of PV solar panel, $R$ is the solar radiation at an instant of time $t$. The reference solar radiation, $R_{r e f}$, usually takes the value of $1000 \mathrm{~W} / \mathrm{m}^{2}$. The reference temperature of the solar cell, $T_{r e f}$, is defined as $25^{\circ} \mathrm{C}$. The ambient temperature is represented by $T_{\text {air }}$ and finally, $N_{T}$ and NOCT are parameters specific to the manufacturer, representing the temperature coefficient and the operational temperature in Celsius degrees respectively.

The state of the battery bank is given by the Equation 4 for charge energy and Equation 5 for discharge energy. This model depends on the monitoring of load and the generation of the renewable system [25].

$$
\begin{gathered}
E_{b, c e}(t)=E_{b}(t-1)(1-\sigma) \\
+\left\{\frac{\left[\left(E_{p v}(t) \eta_{i n v}+E_{w t}(t) \eta_{i n v}^{2}\right)-\frac{E_{c a}(t)}{\eta_{i n v}}\right]}{\eta_{b a t}{ }^{-1}}\right\}, \\
E_{b, c e}(t)=E_{b}(t-1)(1-\sigma) \\
-\left\{\frac{\left[\frac{E_{c a}(t)}{\eta_{i n v}}-\left(E_{p v}(t) \eta_{i n v}+E_{w t}(t) \eta_{i n v}^{2}\right)\right]}{\eta_{b a t}}\right\}, \\
E_{w t}(t)=N_{w t} P_{w t}(t), \\
E_{p v}(t)=N_{p v} P_{p v}(t),
\end{gathered}
$$

where $E_{b}(t-1)$ is the state of battery bank in the instant $t-1 ; \sigma$ is the auto-discharge ratio over one hour, $\eta_{\text {inv }}$ is 
the inverter efficiency, $\eta_{b a t}$ is the battery efficiency, $E_{c a}(t)$ is the energy demand in the instant time $t . E_{w t}(t)$ and $E_{p v}(t)$ are the WT system (Equation 6) and PV system (Equation 7) total generation, respectively [25]. $N_{w t}$ is the number of wind turbines and $N_{p v}$ is the number of solar PV panels in the HRES. Equation 4 is employed when the sum of wind and solar generation is higher than the load $\left(E_{w t}(t)+E_{p v}(t)>E_{c a}(t)\right)$ and Equation 5 is used when the load or demand energy is higher than the renewable energy production $\left(E_{w t}(t)+\right.$ $\left.E_{p v}(t)<E_{c a}(t)\right)$. The minimum charge state of the battery bank must also be taken into consideration, in this case as:

$$
E_{b, \min }=(1-D O D) S_{b}
$$

where $D O D$ is the maximum discharge percent and $S_{b}$ is the nominal capacity of one battery [25].

Being defined as a percentage variable, $L P S P=0 \%$ means that the energy output meets the demand profile; on the contrary, value of $100 \%$ means that the total load demand is not satisfied by the system. Hourly values of load and electricity generation are used to evaluate the yearly variation of the LPSP according to Equation 9:

$$
L P S P=\frac{\sum_{t=1}^{8760}\left[E_{c a}(t)-E_{g e n}(t)\right]}{\sum_{t=1}^{8760} E_{c a}(t)},
$$

where $E_{g e n}(t)$ is given by the sum of the wind, PV generation, and the contribution of the battery bank [25]. If $L P S P<0$ then the energy output exceeds the load profile; if on the contrary, LPSP $>0$ the demand is exceeding the power output.

The mathematical expression for LCOE is given by Equation 10, which determines the value in USD of each $\mathrm{kWh}$ of energy production, relating the initial capital, operation and maintenance, and replacement costs, with the annual energy load or demand [26]. Equation 11 defines the Capital Recovery Factor $(C R F)$ in terms of the life-time of the HRES $a$ and the interest rate ir [25], [26], which for this study were considered as 20 years and 5\%, respectively. TLCC is the Total Life Cycle Cost and is given in USD by Equation 12 for wind power, by Equation 13 for the PV panels and for the battery bank the TLCC is given by Equation 14 [26].

$$
\begin{gathered}
L C O E=\frac{T L C C \times C R F}{\sum_{t=1}^{8760} E_{c a}(t)}, \\
C R F=\frac{i r(1+i r)^{a}}{(1+i r)^{a}-1}, \\
T L C C_{w t}=N_{w t} x C_{c, w t} x\left(1+\frac{o \& M_{w t}}{C R F}\right), \\
T L C C_{p v}=N_{p v} x C_{c, p v} x\left(1+\frac{o \& M_{p v}}{C R F}\right), \\
T L C C_{b b}=E_{b, \max } x I_{b b}+\frac{C_{R} x E_{b, \max }}{C R F} \\
+\frac{M_{b b} x F_{\max } x E_{b, \max }}{C R F},
\end{gathered}
$$

Here $N_{w t}$ is the number of wind turbines, $C_{c, w t}$ is the initial capital cost of wind turbine, $O \& M_{w t}$ is the operation and maintenance costs of the wind turbine over one year. Additionally, $N_{p v}$ is the number of PV solar panels, $C_{c, p v}$ is the initial capital cost of PV panels, $O \& M_{p v}$ is the operation and maintenance costs of the PV panels over one year. Similarly, $E_{b, \max }$ is the total storage capacity of battery bank, $I_{b b}$ is the initial cost for each $\mathrm{kWh}$ of capacity in the battery bank, $M_{b b}$ is the maintenance cost for each $\mathrm{kW}$ over one year, $F_{\text {max }}$ is the maximum charge or discharge rate over one hour (given in $\%$ ), and $C_{R}$ is the annual cost of replacement of batteries [26].

This study does not consider the battery bank operational cost, since this is smaller than the capital and maintenance costs. Additionally, the presented model for the $T L C C_{b b}$ does not involve the cost of power equipment. A full implementation is presented for instance by Malheiro et al. [26]. Other authors only consider the capital cost for the batteries replacement in their models like Maleki and Pourfayaz [25]. In this sense, the total life cycle cost is the sum between $T L C C_{w t} T L C C_{p v}$ and $T L C C_{b b}$.

\section{Methodology}

The current methodology proposes an initial characterization of the demand at a location of interest; subsequently, the wind and irradiance resource data for this site is acquired. An optimal sizing of the HRES is then determined by means of GA with a refinement in the area for PV generation by considering V-Through (VT) concentration in the final computation.

The current case study consists in a rural area representative of the center of Colombia with available information on renewable resources [27]. The wind speed and temperature profile were extracted from station 205 (Santa Elena-Radar) and the solar radiation profile was extracted from data of the station 6001 (Piranómetro Torre SIATA) measured during 2018. Considering a ZNI or off-grid application, the behavior of energy demand can be determined from active energy policies [28], For this work, a normalized approximate consumption of 3.6 $\mathrm{kWh}$ /day was determined.

For the wind turbine models under consideration, $O \& M_{w t}$ values were estimated to be $4 \%$ of $C_{c, w t}$. Similarly, Table 1 presents the PV panels considered in the study, where $C_{c, p v}$ was estimated as an average between the cost reported by $\mathrm{Fu}$ et al. [29] and Fraunhofer [30], and $O \& M_{p v}$ equivalent to $1 \%$ of $C_{c, p v}$. Finally, Table 2 shows the features of the battery model.

This work focuses on the sizing of HRES through genetic algorithms. The GA begins with the creation of the initial population which is composed of $p$ individuals with $n$ chromosomes. Each chromosome represents the number of wind turbines, solar panels, and batteries. The first four chromosomes correspond to the wind turbines (Nw1 to $N w 4)$, the next three chromosomes correspond to the considered PV units ( $N p v 1$ to $N p v 3)$ and the last chromosome, $\mathrm{Nb}$, represents the amount of batteries in the storage system. In total, the proposed solution is composed of 8 chromosomes $(n=8)$. Initially a random 
population is created to evaluate the objective function, presented in Equation 15:

$$
M=w_{T} L P S P+w_{E} L C O E
$$

where $w_{T}$ is the weight of the technical indicator LPSP and $w_{E}$ is the weight of the economic indicator $L C O E$, therefore, the sum between $w_{T}$ and $w_{E}$ is equal to 1 . This is a method to calculate a multi-objective function that incorporates two different functions. Here the best individual minimizes the value of $M$. Subsequently, the decision is to continue with the algorithm if the best individual has an acceptable value of LPSP within the desired range and if the number of iterations established for the study has not reached its limit. If the LPSP value of the best individual according to $M$ is not within the desired range or the maximum number of iterations is reached, the algorithm is terminated by taking the best individual. When the algorithm continues after the decision is made, the parents are selected, to be the individuals with smallest $M$ values. The algorithm continues until the maximum number of iterations is reached or when $L P S P$ is greater than $2 \%$, obtaining the best solution of the problem with the minimum values of the LPSP and LOCE for the multi-objective function M.

For this work, $w_{T}$ is equal to 0.7 and $w_{E}$ is equal to 0.3 , so the priority of the algorithm is to find a solution that meets the demand and then satisfies the economic criteria. The parameters of the GA are a population with 16 individuals with chromosome values between 0 and 50 , the parent's number is 8 , the crossover was to one point on the mean point, and the mutation took a value of $3 \%$ of the total number of the chromosomes of the sons.

Table 1. Data for the considered PV solar panels models

\begin{tabular}{cccc}
\hline Parameter & Model 1 & Model 2 & Model 3 \\
\hline$P_{p \vee r}[\mathrm{~W}]$ & 100 & 200 & 300 \\
Area $\left[\mathrm{m}^{\wedge} 2\right]$ & 0,69 & 1,32 & 1,94 \\
Efficiency & 0,146 & 0,151 & 0,155 \\
$N O C T\left[{ }^{\circ} \mathrm{C}\right]$ & 45 & 45 & 47 \\
$T_{r e f}\left[{ }^{\circ} \mathrm{C}\right]$ & 25 & 25 & 25 \\
$N_{T}\left[1 /{ }^{\circ} \mathrm{C}\right]$ & $-0,0038001$ & $-0,0038001$ & $-0,00408$ \\
$C_{c, p \mathrm{v}}[\mathrm{USD}]$ & 175 & 350 & 525 \\
$O \& M_{p \mathrm{v}}[\mathrm{USD}]$ & 1,75 & 3,5 & 5,25 \\
\hline
\end{tabular}

Table 2. Data of Battery considered

\begin{tabular}{cc}
\hline Parameter & Value \\
\hline$S_{b}[\mathrm{kWh}]$ & 1,35 \\
$\eta_{b a t}$ & 0,85 \\
$D O D$ & 0,8 \\
$F_{\max }$ & 0,08 \\
$\sigma$ & 0,0002 \\
$\eta_{i n \mathrm{v}}$ & 0,95 \\
$I_{b b}[\mathrm{USD} / \mathrm{kWh}]$ & 96.3 \\
$M_{b b}[\mathrm{USD} / \mathrm{KW}-\mathrm{year}]$ & 5 \\
\hline
\end{tabular}

The photovoltaic concentration system is designed with the VTDesign ${ }^{\circledR}$ software, in which the following entries must be defined. The length of the panel $\left(I_{P V}\right)$, the length of the right $\left(L_{R}\right)$ and left $\left(L_{L}\right)$ mirrors, the tilt angle of the right $\left(M_{R}\right)$ and left $\left(M_{L}\right)$ mirrors, the elevation angle of the PV panel $(\beta=0)$, the costs of the panel (taken from the supplier), the costs of the glass and the structure [31], all these in dollars per square meter $\left(\mathrm{USD} / \mathrm{m}^{2}\right)$, the elevation path of the sun at the location $(0<\alpha<180)$, the reflection index of the mirror ( $\rho=$ 0.86 ) and finally if manual sun tracking is to be used by adjusting the system at certain times of the day, where $\left(\beta_{i}\right)$ is the initial angle, $\left(\beta_{\alpha s}\right)$ is the step in $\alpha$ and $\left(\beta_{s}\right)$ is the variation in degrees of every step.

To determine the best option in terms of costefficiency $\left(I_{C O E}\right)$, four implementations are proposed to solve the problem, see Table 3.

- Iref It is the reference panel without any type of concentrator or solar tracking system.

- Ia It is the panel with the V-trough concentrator, but without the solar tracking system.

- Ib It is the panel with the V-trough concentrator and the solar tracking system in two positions throughout the day.

- Ic It is the panel without the concentrator and with the solar tracking system in two positions during the day.

Table 3. VTDesign parameters

\begin{tabular}{ccccccc}
\hline \multicolumn{7}{c}{ Parameters } \\
\hline Set-up & $I_{P V}$ & $L_{L}$ & $L_{R}$ & $M_{L}$ & $M_{R}$ & $\beta_{i}, \beta_{\alpha s}, \beta_{S}$ \\
& $(\mathrm{~m})$ & $(\mathrm{m})$ & $(\mathrm{m})$ & $\left(^{\circ}\right)$ & $\left(^{\circ}\right)$ & $\left(^{\circ}\right)$ \\
Iref & 0.99 & 0 & 0 & 0 & 0 & $0,0,0$ \\
$I a$ & 0.99 & 0.99 & 0.99 & 25 & 25 & $0,0,0$ \\
$I b$ & 0.99 & 0.99 & 0.99 & 25 & 25 & $60,60,60$ \\
$I c$ & 0.99 & 0 & 0 & 0 & 0 & $60,60,60$ \\
\hline
\end{tabular}

\section{Results}

The GA routine was used to evaluate several configurations of the HRES. Table 4 presents only five of the alternatives evaluated that presented the values of LPSP closest to $0 \%$. In that table is also presented the configuration with the best solution in each case. Figure 2 shows the load profile, and compares it with the electric generation of simulations 16 and 18, which are the closest to the demand. To continue the concentrated PV analysis, for this work the best solution will be the simulation 18 due to the priority of weight of the technical indicator $L P S P$, however, if the priority is the economic factor, it is evident that the best solution is given by the simulation 16. Taking as input the simulation 18 of the GA routine, new simulations are made for the design of the concentrator, where several iterations were made to validate the best alternative and demonstrate if the PV concentration system is an electrically viable option for the proposed case. Table 5 and Figure 3 show that the IC 
implementation is the one that best complies with the cost-efficiency index $\left(I_{C O E}\right)$. This was simulated with manual tracking, which must be set to two schedules with a 60-degree movement. The implementation of $I b$ also proves to be a profitable solution and has the best effective concentration index $\left(C R_{e}\right)$, being the one that best takes advantage of the photovoltaic area, decreasing the size of the panel by $55.7 \%$. Another important result can be noticed in the implementation Ia that even having a concentrator is not a cost-efficient option because in the first and last hours of the day the mirrors block the entry of rays.

Table 4. Results of GA to dimension HRES for Santa Elena residential load

\begin{tabular}{ccccccccccccccc}
\hline Sim. & $\begin{array}{c}\text { LPSP } \\
\text { [\%] }\end{array}$ & $\begin{array}{c}\text { LCOE } \\
\text { [USD/kWh] }\end{array}$ & Nw1 & Nw2 & Nw3 & Nw4 & Npv1 & Npv2 & Npv3 & Nb & $\begin{array}{c}\text { Ewt } \\
{[\%]}\end{array}$ & $\begin{array}{c}\text { Epv } \\
{[\%]}\end{array}$ & $\begin{array}{c}\text { Area } \\
{\left[\mathbf{m}^{2}\right]}\end{array}$ \\
\hline $\mathbf{2}$ & $-89,58$ & 49986,44 & 0 & 0 & 0 & 1 & 0 & 0 & 0 & 49 & 100 & 0 & 0 \\
$\mathbf{3}$ & $-31,77$ & 5,69 & 0 & 0 & 0 & 0 & 5 & 1 & 1 & 49 & 0 & 100 & 6,69 \\
$\mathbf{1 6}$ & $-17,94$ & 6,5 & 0 & 0 & 0 & 0 & 1 & 1 & 2 & 37 & 0 & 100 & 5,88 \\
$\mathbf{1 8}$ & $-12,06$ & 10716,48 & 0 & 1 & 0 & 0 & 0 & 1 & 0 & 49 & 76,55 & 23,45 & 1,32 \\
$\mathbf{2 1}$ & $-24,62$ & 10716 & 0 & 1 & 0 & 0 & 1 & 1 & 0 & 48 & 68,52 & 31,48 & 2,01 \\
\hline & & & & & & & Ic & 0.9544 & 1.5076 & $-33.7 \%$ & 870.44 \\
\hline
\end{tabular}

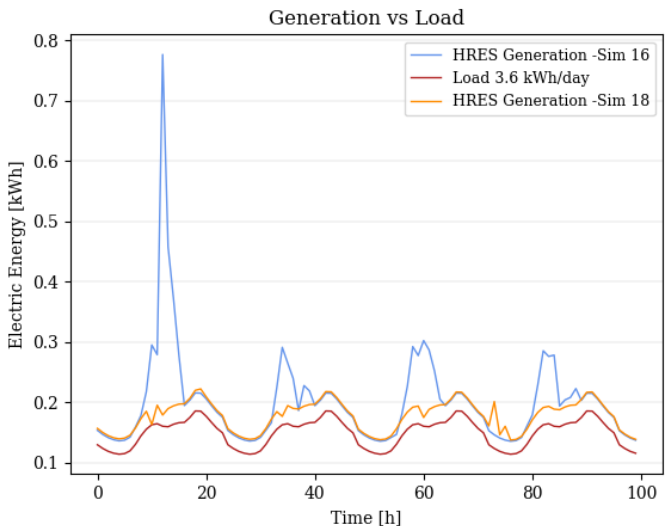

Fig. 2. Generation of HRES vs Load Profile - Case of Study First 100 hours

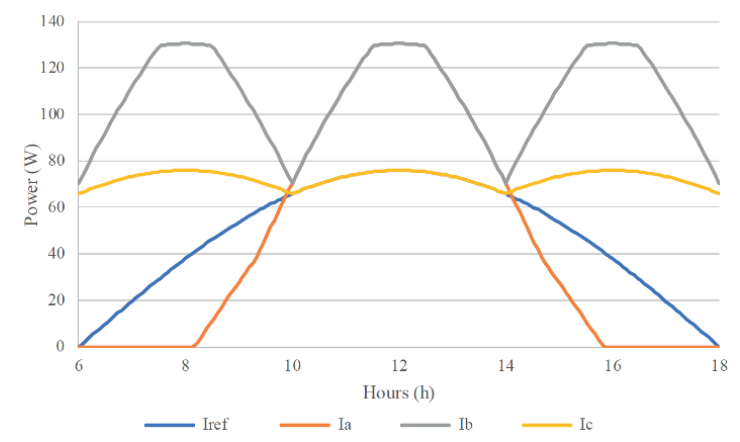

Fig. 3. Optical performance of the different photovoltaic implementation.

Table 5. Implementation of differents Set-ups in VTDesign

\begin{tabular}{ccccc}
\hline \multicolumn{5}{c}{ Results } \\
\hline Set-up & $\boldsymbol{C R}_{\boldsymbol{e}}$ & $\boldsymbol{I}_{\mathrm{COE}}$ & Area (\%) & $\begin{array}{c}\text { Energy } \\
(\boldsymbol{W} / \boldsymbol{h})\end{array}$ \\
Iref & 0.6331 & 1.0 & $0 \%$ & 580.29 \\
$\boldsymbol{I a}$ & 0.6033 & 0.5210 & $+4.9 \%$ & 553.04 \\
$\boldsymbol{I b}$ & 1.4285 & 1.2335 & $-55.7 \%$ & 1304.73
\end{tabular}

\section{Conclusions}

The site of interest has a mean wind speed of about 3.5 $\mathrm{m} / \mathrm{s}$, clearly below the rated wind speed for the wind turbines under consideration. Most commercially available wind turbines are designed for relatively high rated wind speed, since no low-speed alternatives were available, the energy production cannot offset the costs of wind energy. In contrast, the PV energy shows significant participation in HRES on residential load, since it achieved to supply the demand while resulting in lower cost compared to wind energy, this is evident in the solution of simulation 16 and 18 , where the simulation 16 only uses PV energy and, reaches a low value of $L C O E$ of $6.5 \mathrm{USD} / \mathrm{kWh}$. From the above it is possible to infer that for residential application, the HRES with PV and batteries equipment's are more costefficient due to the accessible costs and the necessary area. Additionally, the $L C O E$ is highly sensitive to models including wind turbines, most likely due to high initial capital cost compared to solar technology. This is evident from simulations that exclude wind generation and result in smaller $L C O E$ values. The most costefficient solution is the implementation of the panel with solar tracking and without mirrors, however from the GA simulations in many cases several panels were needed so the solution with mirrors is more viable, due to the reduction in $55 \%$ of the PV area. The use of a VTrough concentrator increases the irradiance density for the solar system by an average of 1.43 , this shows a great alternative because in areas where the available area of installation of panels is reduced such as crops, facades or roofs, implement mirrors as concentrators are very cheap and simple to install. Another important point is that the concentration rate is less than 3 and this does not affect the degradation of the solar cell by the increase in temperature. 


\section{Acknowledgements}

This research has been developed in the framework of the "ENERGETICA 2030" Research Program, with code 58667 in the "Colombia Científica" initiative, funded by The World Bank through the call "778-2017 Scientific Ecosystems", managed by the Colombian Ministry of Science, Technology and Innovation (Minciencias), with contract No. FP44842-210-2018.

\section{References}

1. UPME, Integración de las energías renovables no convencionales en Colombia Integración de las energías en Colombia. 2015.

2. IRENA, "Renewable energy sources," 2018. [Online]. Available: https://www.irena.org/. [Accessed: 01-May-2019].

3. B. Bhandari, S. R. Poudel, K.-T. Lee, and S.-H. Ahn, "Mathematical modeling of hybrid renewable energy system: A review on small hydro-solar-wind power generation," Int. J. Precis. Eng. Manuf. Green Technol., vol. 1, no. 2, pp. 157-173, 2014, doi: 10.1007/s40684-014-0021-4.

4. "WEC Energy Trilemma Index Tool," 2018. [Online]. Available: https://rilemma.worldenergy.org/\#!/energy-index. [Accessed: 09-Apr-2019].

5. A. Askarzadeh, "A novel metaheuristic method for solving constrained engineering optimization problems: Crow search algorithm," Comput. Struct., vol. 169, pp. 1-12, 2016, doi: 10.1016/j.compstruc.2016.03.001.

6. S. Twaha and M. A. . Ramli, "A review of optimization approaches for hybrid distributed energy generation systems: Off-grid and gridconnected systems," Sustain. Cities Soc., vol. 41, pp. 1-19, 2018.

7. S. R. Tito, T. T. Lie, and T. N. Anderson, "Optimal sizing of a wind-photovoltaic-battery hybrid renewable energy system considering sociodemographic factors," Sol. Energy, vol. 136, pp. 525-532, 2016, doi: 10.1016/j.solener.2016.07.036.

8. V. Khare, S. Nema, and P. Baredar, "Solar-wind hybrid renewable energy system: A review," Renew. Sustain. Energy Rev., vol. 58, pp. 23-33, 2016, doi: 10.1016/j.rser.2015.12.223.

9. T. Khatib, A. Mohamed, and K. Sopian, "Optimization of a PV/wind micro-grid for rural housing electrification using a hybrid iterative/genetic algorithm: Case study of Kuala Terengganu, Malaysia," Energy Build., vol. 47, pp. 321-331, 2012, doi: 10.1016/j.enbuild.2011.12.006.

10. G. Merei, C. Berger, and D. U. Sauer, "Optimization of an off-grid hybrid PV-WindDiesel system with different battery technologies using genetic algorithm," Sol. Energy, vol. 97, pp. 460-473, 2013, doi: 10.1016/j.solener.2013.08.016.
11. A. Kamjoo, A. Maheri, A. M. Dizqah, and G. A. Putrus, "Multi-objective design under uncertainties of hybrid renewable energy system using NSGA-II and chance constrained programming," Int. J. Electr. Power Energy Syst., vol. 74, pp. 187-194, 2016, doi: 10.1016/j.ijepes.2015.07.007.

12. M. B. T. Fogaing, H. Gordon, C. F. Lange, D. H. Wood, and B. A. Fleck, Concentrated Photovoltaic $(C P V)$ : From Deserts to Rooftops, vol. 70. Springer International Publishing, 2019.

13. Q. Xuan et al., "Overall detail comparison for a building integrated concentrating photovoltaic/daylighting system," Energy Build., vol. 199, pp. 415-426, 2019, doi: 10.1016/j.enbuild.2019.07.018.

14. H. Hadavinia and H. Singh, "Modelling and experimental analysis of low concentrating solar panels for use in building integrated and applied photovoltaic (BIPV/BAPV) systems," Renew. Energy, vol. 139, pp. 815-829, 2019, doi: 10.1016/j.renene.2019.02.121.

15. A. Mourant, "BIPV: Better form, improved function," Renew. Energy Focus, vol. 15, no. 5, pp. 20-23, 2014, doi: https://doi.org/10.1016/S17550084(14)70115-2.

16. A. Arias--Rosales and R. Mej $\rangle^{\prime} \backslash$ ia--Gutiérrez, "Modelling and simulation of direct solar radiation for cost-effectiveness analysis of V-Trough photovoltaic devices," Int. J. Interact. Des. Manuf., vol. 10, no. 3, pp. 257-273, 2016.

17. R. Leutz and H. P. Annen, "Reverse ray-tracing model for the performance evaluation of stationary solar concentrators," Sol. energy, vol. 81, no. 6, pp. 761-767, 2007.

18. J. E. Cotter, "RaySim 6.0: a free geometrical ray tracing program for silicon solar cells," in Conference Record of the Thirty-first IEEE Photovoltaic Specialists Conference, 2005., 2005, pp. 1165-1168.

19. T. Woolmington, K. Sunderland, J. Blackledge, and M. Conlon, "The progressive development of turbulence statistics and its impact on wind power predictability," Energy, vol. 77, pp. 25-34, 2014, doi: 10.1016/j.energy.2014.03.015.

20. Small Wind Certification Council, "Bergey Excel 6 SWCC Summary Report," 2014.

21. Small Wind Certification Council, "Kestrel e400nb SWCC Summary Report," 2015.

22. Small Wind Certification Council, "Kingspan KW6 SWCC Summary Report," 2014.

23. Small Wind Certification Council, "Endurance S343 SWCC Summary Report," 2014.

24. A. Orrell, N. Foster, S. Morris, and J. Homer, "2016 distributed wind market report," 2017.

25. A. Maleki and F. Pourfayaz, "Optimal sizing of autonomous hybrid photovoltaic / wind / battery power system with LPSP technology by using evolutionary algorithms," Sol. Energy, vol. 115, pp. 
471-483, 2015, doi: 10.1016/j.solener.2015.03.004.

26. A. Malheiro, P. M. Castro, R. M. Lima, and A. Estanqueiro, "Integrated sizing and scheduling of wind/PV/diesel/battery isolated systems," Renew. Energy, vol. 83, pp. 646-657, 2015, doi: 10.1016/j.renene.2015.04.066.

27. Alcaldia de Medellín and Área Metropolitana del Valle de Aburra, "SIATA, Radar Meteorologico." 2018.

28. IPSE, "Instituto de Planeación y Promoción de Soluciones Energéticas para las Zonas No
Interconectadas.” 2019.

29. R. Fu, D. Feldman, and R. Margolis, "U.S. Solar Photovoltaic System Cost Benchmark: Q1 2018," Nrel, no. Novmnber, pp. 1-47, 2018, doi: 10.7799/1325002.

30. Fraunhofer, "Fraunhofer ISE: Photovoltaics Report," Fraunhofer ISE, no. March, p. 47, 2019.

31. C. S. Sangani and C. S. Solanki, "Experimental evaluation of V-trough (2 suns) PV concentrator system using commercial PV modules," Sol. energy Mater. Sol. cells, vol. 91, no. 6, pp. 453-459, 2007. 